\title{
An Automated Selecting Subcontractor Model In E-Commerce
}

\author{
by
}

\author{
Pao-Hung Lin
}

\author{
Asst. Prof., Dept. of Civil Engineering, Feng-Chia University, Taichung, Taiwan \\ E-mail:paolin@fcu.edu.tw
}

\begin{abstract}
From the observation of organization changes in digital economy, the features of organization expansion from its concentrated kernel to the globalized ecommerce scope is identified to rebuild the relationships and connections between the whole subcontracting supply chain for construction projects. An automated subcontracting selection model is proposed and the final decision-making for selection will be approached by Multiple Attribute Utility Theory. Following this methodology, it can be expected to bring the excellent decision support into full play for the selection of subcontractors.
\end{abstract}

\section{KEYWORDS: utility theory, e-commerce, subcontract, decision-making}

\section{INTRODUCTION}

Knowledge-based and networked characteristics shape the all new information era in the digital economy. "Electronic Commerce" (e-commerce) has been the symbol of enterprise activities in digital time. The force of virtualization and virtual market constitutes the heart of ecommerce in the digital economy. The nature of e-commerce is to build the innovation of competitive advantage between enterprises by way of web connection, to alter the operation process and to enhance the efficiency of organization. Digitization not only improves the information quality and enables interactivity, but also provides a powerful approach for management in many respects. The new economy is creating a reformation of conflicting drivers causing every enterprise in every industry to rethink its competitive advantage, to rebuild its system of value chain, and to restructure its organization pattern. All the traditional thinking way to communication or transaction is facing the unprecedented challenges to shift.

Tapscott (1996) pointed that the result of this shift from physical to virtual does not simply reduce redundancy and speed up communication. Rather, the substantial changes in the essence of human and organizational communication occur. Inter-enterprise computing is causing new economic dynamics in the following ways: accessibility of partners, new interdependence, interorganizational metabolism, cooperative competitiveness, and interorganization value creation. Through the connection of information network, the resources are distributed and values are generated in the boundless virtual marketplace.

Due to the sharp differences between the "virtual market" transaction atmosphere in the postinformation era and the traditional physically economic market, major impact are certain to occur within traditional main contractor and subcontractor relations. The processes of these change, and whether they will completely alter previous subcontracting relationships and models is a topic worthy of further research and consideration. From comparisons of the construction industry with the manufacturing industry or other productions that have gone through relatively little in the way of developing IT environment, it is quite clear that, based on the ideas of e-commerce and the importation of practical methods, in the future it will be possible to improve on abuses that arise in traditional construction industry business processes.

Although it's crucial to select appropriate subcontractors to implement specific construction project, few research really touched the selection techniques and methodologies and extended further into the connection of overall 
supply chain. Therefore, what the influence to the whole subcontracting supply chain of the research's concern in this digital economy is analyzed from the new vision of economics of electronic commerce. The new transaction mechanism is shaping in digital economy and all the trends and properties existing in the omnipresent environment have resulted in great change of organizational structure and the nature of transaction, and even paradigm shift.

\section{METHODOLOGY}

The methodology of this research is founded on the observation of e-commerce economics as well as networking mechanism and put the problem in center of subcontracting supply chain management or the combination of subcontractors. The major significance of this methodology is to support the acquisition of optimal selection set from myriad subcontracting combinations for specific construction project. All the bidding information and decision are implemented through omnipresent Internet. Every client user needs only to open their web browser to use the system's capabilities to retrieve all of the needed information online. The architecture of data transformation can be shown as Figure 1. Further, this methodology is proposed by taking advantage of the portfolio theory of investment choice under conditions of uncertainty on the mean and the variance of the distributions of returns to approach the selection model of subcontractors in construction project. That is, the risky connection in whole supply chain will be considered and obviously the profit will no longer be the only factor to the decision-making of bidder selection as the traditional bidding strategy. And most importantly, the factor that must be taken into consideration in electronic bidding system is how to provide a compatible environment and services meeting the needs of all participating enterprises of the global market in a timely and sharing manner.

This methodology also extends the decision manner of two factors of portfolio theory to multiple attribute decision-making in order to be endowed with potential for encompassing all the possible factors of influence to selection. The final selection will be dependent on the risk preference of decision-maker by the utility function. Comprehensively, the methodology is enclosed by the internet-based information technology as the demonstration of Figure 2.

\section{$3 . \quad$ NETWORKING MECHANISM}

In retrospection of the development of commercial organization, there can be classified as function oriented, department oriented, and the matrix type in traditional organization categories (Miles and Snow, 1992). Nevertheless, "networking" has been the main research focus in management field and the trend to the application of reality. There are many different denominations to interpret the remold organization, such as Peter Drucker's (1998) "Networked Organization," Peter Senge's "Learning Organization," Keen's (1991) "Relational Organization" and Davidow and Malone's (1992) "Virtual Organization." They all put emphasis on the "relational" network between members of organization. No matter what the idea of networking interpreted from the view point of resource dependence (Joanson and Mattsson, 1987), transaction cost (Williamson, 1975; Oliver, 1990), or strategic alliance (Porter and Fuller, 1987), the essence of networking lies on that the specific enterprise can concentrate on the most valuable activities with competitive advantages, to reach the economies of scale and obtain the benefit of work specialization (Porter, 1985). The "networked organization" opens a new style and feature in the area of organization structure and strategic management, revives the traditional organization pattern (Miles and Snow, 1992), and provides the alternatives except vertical integration as well as diversification.

From the investigation and observation of the evolutionary process in traditional organization relationship, it can be found that the "information network" is indeed playing a very crucial role to push the changes and virtualization (Tang, 1998). Figure 3 represents the process of organization development under both the coordinate axes of relation network and information network. It demonstrates the features of organization expansion from its limited kernel, partnership, vertical integration, outsourcing to the e-commerce global scope according with the developing information network, and simultaneously expresses the virtualized evolution of organization relationship. Also, the corresponding space-time situation of this research's concerns are located on the relation plane to show the focus of the 
present model. Additionally and importantly, this research is not only focusing on the exploration of the forming of virtual organization, but on the searching of the profit-base and efficiency to improve the link of selecting subcontractors by observing the organization changes in digital economy.

\section{THE PRESENT CONCEPTUAL MODEL}

The proposed selection model takes three main attributes into subcontracting consideration, namely, the expected return $(E R N)$, the planned performance dispersion (PPD), and the comprehensive risk index $(C R I)$. The expected return and the planned performance dispersion are the leading roles and have been exactly discussed by Tserng and Lin. This research, the comprehensive risk index is to integrate the bidder's credit degree and quotation deviation (including tender price and duration) to expansively consider the correlation between subcontractors in the specific combination of construction project. In the concrete, the $C R I$ is a representative evaluation index composed by three kinds of uncertainty $\alpha_{i j}, \beta_{i j}$, and $\gamma_{i}$, where $\alpha_{i j}$ is the measurement of dispersed degree of quoted duration for subcontractor $i$ to the market value in the bidding of specific subproject $j ; \beta_{i j}$ is the measurement of dispersed degree of quoted price for subcontractor $i$ to the market value in specific subproject $j$; and $\gamma_{i}$ is the credit rating for subcontractor $i$ evaluated by the general contractor in advance. Expressed in equation form and taken the absolute value in numerator to eliminate the negative situation, it shows

that

$\alpha_{i j}=\frac{\left|Q_{D_{i j}}-\mu_{D_{j}}\right|}{\sigma_{D_{j}}} \quad(e q-1)$

in which $Q_{D_{i j}}$ is the quoted duration of subcontractor $i$ in the bidding of specific subproject $j ; \mu_{D_{j}}$ is the mean value of all quoted duration in bidding market for specific subproject $j ; \sigma_{D_{j}}$ is the standard deviation of all quoted duration in bidding market for specific subproject $j$. In the same way, $\beta_{i j}$ can be obtained. The present model denominates the comprehensive uncertainty of $(\alpha \bullet \beta \bullet \gamma)$ as "quasi$\sigma$ ", compared with the physical variance $\sigma^{2}$ of specific asset returns in portfolio theory. Thus, it can be expressed as following equation

$$
\sigma_{q}=\alpha \cdot \beta \cdot \gamma \quad(e q-2)
$$

From portfolio theory, the comprehensive risk index $C R I$ can be expressed as

$$
\begin{aligned}
& C R I^{2}=\sum_{i=1}^{n} x_{i}^{2}\left(\sigma_{q}\right)_{i}^{2}+2 \sum_{\substack { i=1 \\
\begin{subarray}{c}{j=1 \\
j>i{ i = 1 \\
\begin{subarray} { c } { j = 1 \\
j > i } }\end{subarray}}^{n} x_{i} x_{j}\left(\sigma_{q}\right)_{i j} \quad(e q-3) \\
& =\sum_{i=1}^{n} x_{i}^{2}\left(\sigma_{q}\right)_{i}^{2}+2 \sum_{i=1}^{n} \sum_{\substack{j=1 \\
j>i}}^{n} x_{i} x_{j} \rho_{i j}\left(\sigma_{q}\right)_{i}\left(\sigma_{q}\right)_{j} \quad(e q-4)
\end{aligned}
$$

where the proportion coefficient $x_{i}$ in portfolio theory, here represents the weight factor which is equal to the ratio of the quoted price of specific subcontractor $i$ or $j$ to the quoted summation of the whole selected combination; and $\rho_{i j}$ is the coefficient of correlation between subcontractor $i$ and $j$.

The present conceptual model combined three attributes is depicted as Figure 4 in the space constructed by $E R N, P P D$, and $C R I$ three dimensions. Straightly, the concept model is adherent to the two-attribute model of portfolio selection to demonstrate it in 3-D space. However, it is quite different and much more complicated to find the solution between the utility function surface and nondominated frontier surface in 3-D space than it is in the 2-D space. As a matter of fact, the mathematical construction of utility function surface and nondominated frontier surface is a very difficult task. Therefore the present model will take the multiattribute utility theory to search for the finally optimal selection for decision-making.

\section{DECISION-MAKING MODEL}

As stated in relevant literature, multiattribute utility theory evaluates utility functions intended to accurately express a decision-maker's outcome preferences in terms of multiple attributes. It really reduces the complex problem of assessing a multiattribute utility function into one of assessing a series of unidimensional utility functions. Accordingly, the three concerned attributes of $E R N, P P D$, and $C R I$ in the present model are individually appraised by the preference of decision-maker. From Keeney's (1993) theorem, under the assumption of mutual preferential independence and mutual utility independence of the three attributes, the 
utility function can be expressed as either the multiplicative function or the additive function. That is, the following equations:

$U_{o b j}=\left[\prod_{i=1}^{3}\left(1+k k_{i} u_{i}\left(x_{i}\right)\right)-1\right] / k \quad, \sum_{i=1}^{3} k_{i} \neq 1 \quad(e q-5)$

or

$U_{o b j}=\sum_{i=1}^{3} k_{i} u_{i}\left(x_{i}\right), \quad \sum_{i=1}^{3} k_{i}=1$

where $U_{o b j}$ is the objective function of utility; $k$ is the scaling constant; and $u(x)$ is the individual utility function for each attribute. The three attributes in decision-making will also be normalized to satisfy with the condition that the summation of all weighted scaling constants is equal to one. Exactly, the additive utility function of Equation 2 is held in the present model to formulate the objective function:

$$
\text { Maximize } \quad U_{o b j}=\sum_{i=1}^{3} k_{i} u_{i}\left(x_{i}\right), \quad \sum_{i=1}^{3} k_{i}=1 \quad(e q-7)
$$

The maximum utility value implies the optimal selection for the combination of subcontractors. The solution for Equation 3 is necessary to decide the scaling constants and individual utility functions. The method of determining weights in additive utility models includes multivariate linear (MLR) or non-linear regression analysis, analytical hierarchy process (AHP), direct decomposed tradeoffs and so on (Schoemaker and Waid, 1982). In general, it can be separated into statistical versus subjective approaches. For simplicity and practical purposes, the present operation on weights will thoroughly leave to the arbitrary setting by the decision-maker. More, the sensitivity analysis will be tested to evaluate the changing influences of each weight. Consequently, the procedures for assessing individual utility functions unquestionably become the most significant key point in the present model.

Utility theory assumes that a decision-maker can choose among the alternatives available to the individual to meet the maximum satisfaction degree in individual preference. This can be certainly implied the individual is aware of those alternatives and is capable of evaluating them through "utility function." Moreover, relative to a series of objectives it is assumed all information belonging to the various levels of the objectives can be captured by an individual's utility function. In effect, a utility function is simply a mapping of the values in the range of an attribute into a cardinal worth scale and can be stated as a formal, mathematical representation of individual preference structure. Thus if an individual conforms to specific axioms, a utility function can be constructed. Utility functions have been used extensively in consumer demand theory and economics, and they have been applied to private and public decision-making problems (Goicoechea et al., 1982). For multiobjective problems utility functions can completely order the set of nondominated objectives. The nondominated solution which yields the highest utility is referred to as the best-compromise solution.

\section{CONCLUSION}

The present model system is constructed under the internet-based environment. All the participants in this system are necessarily provided with the basic requirements and functions for web-usage. In other words, the initial investment to build up a suitable networking environment is indispensable to this system. Under the current developing environment, the testing case had ever been completely dealt with in a few minutes to provide decision-making support following this methodology. Although it is very difficult to evaluate the precisely quantitative benefit and economic efficiency between the traditional way to subcontract and the present methodology, it can be greatly expected to reduce the overall amount of time and capital required for the complicated process of procurement. Above of all, it apparently enhances the potential ability to maximize the preferred degree of decision maker's utility in a scientific manner. In spite that the system performance is highly dependent on the computing complexity of raising problems and it will also be compressed by the bandwidth capacity as well as the flow of web transportation thereupon, nevertheless, the present model indeed brings excellent decision support into full play for the selection of subcontractors.

\section{REFERENCES}


1. Davidow, W. H. and Malone, M. S., The Virtual Corporation, Harper Collins Publishing, N.Y., 1992.

2. Drucker, P. E., "The Coming of the New Organization," Harvard Business Review, Vol. 66, No. 1, 1988, pp. 45-53.

3. Goicoechea, A, Hansen, D. R. and Duckstein, L., Multiobjective Decision Analysis with Engineering and Business Applications, Wiley Publishing, New York, 1982.

4. Johansson, J. and Mattsson, L. G., "Interorganizational Relations in Industrial System: A Network Approach Compared with the Transaction-Cost Approach," International Studies of Management and Organization, Vol. 17, No. 1, pp. 34-48, 1987.

5. Keeney, R. L. and Raiffa, H., Decisions with Multiple Objectives: Preferences and Value Tradeoffs, Cambridge University Press, 1993.
Failure in Network Organizations," California Management Review, Vol. 35, 1992, pp. 53-72.

8. Oliver, E. C., "Determinant of Interorganizational Relationships: Integration and Future Directions," Academy of Management Review, Vol. 15, No. 2, 1990, pp. 241-265.

9. Tang, H. C., Study of Construction of Virtual Organization Model From Network Perspective, Example: the Electronics and Information Industries, Ph.D. Dissertation, Graduate School of Business, National Taiwan University, 1998.

10. Tapscott, D., The Digital Economy: Promise and Peril in the Age of Networked Intelligence, McGraw-Hill, N.Y., 1996.

11. Tserng, H. P. and Lin, P. H., "An Accelerated Subcontracting And Procuring Model for Construction Projects," International Journal of Automation in Construction, 2002, pp. 105-125.

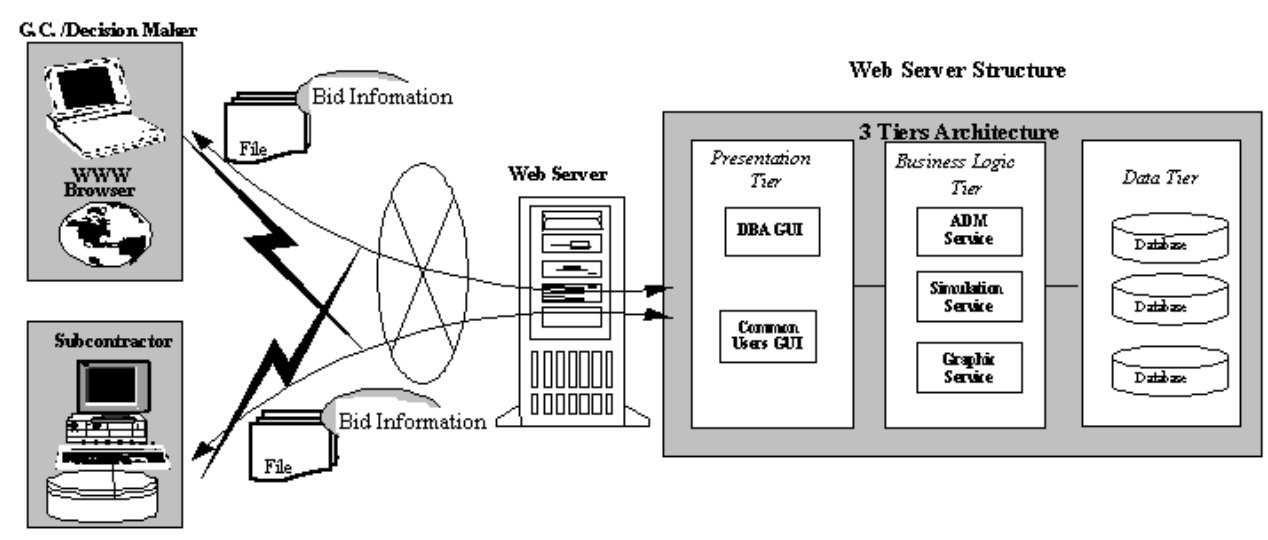

Figure 1. Architecture and Data Transformation of the Present Model

6. Keen, P. G. W., Shaping the Future: Business Design through Information Technology, Harvard Business School Press, 1991.

7. Miles, R. E. and Snow, C. C., "Cause of 


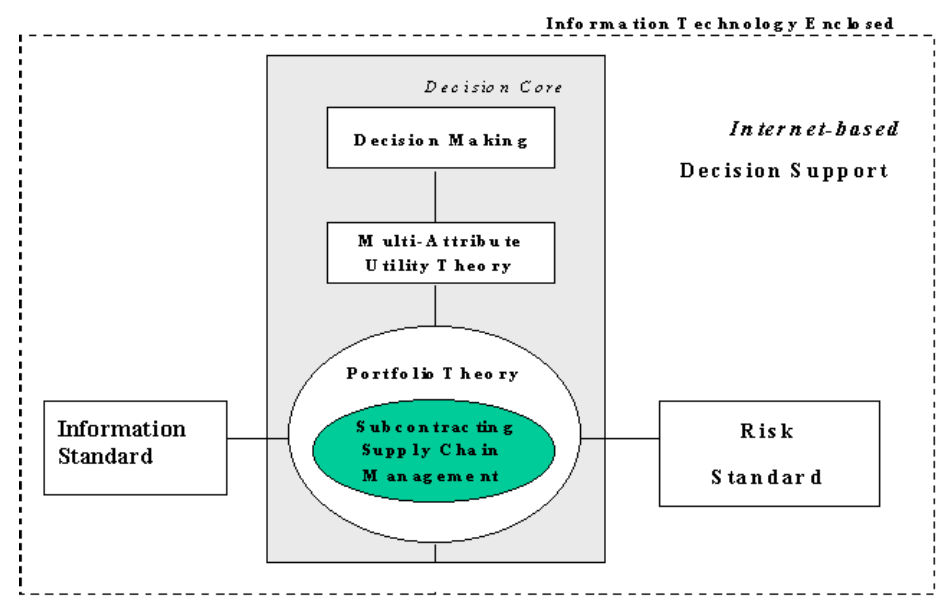

Figure 2. Methodology of The Present Model

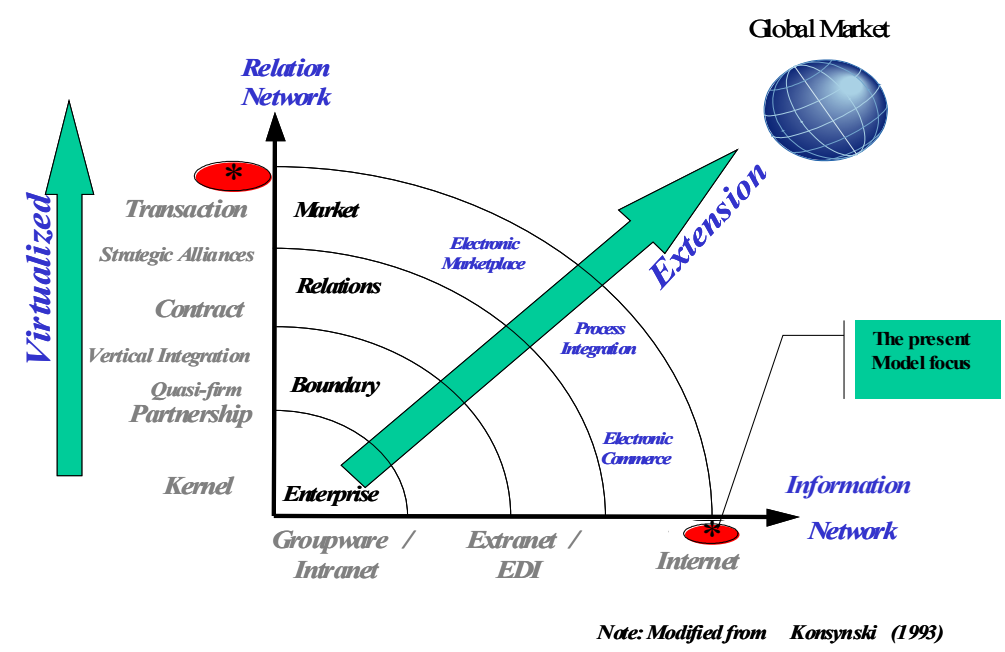

Figure 3. Evolution of Organization Type Under Networking Mechanism

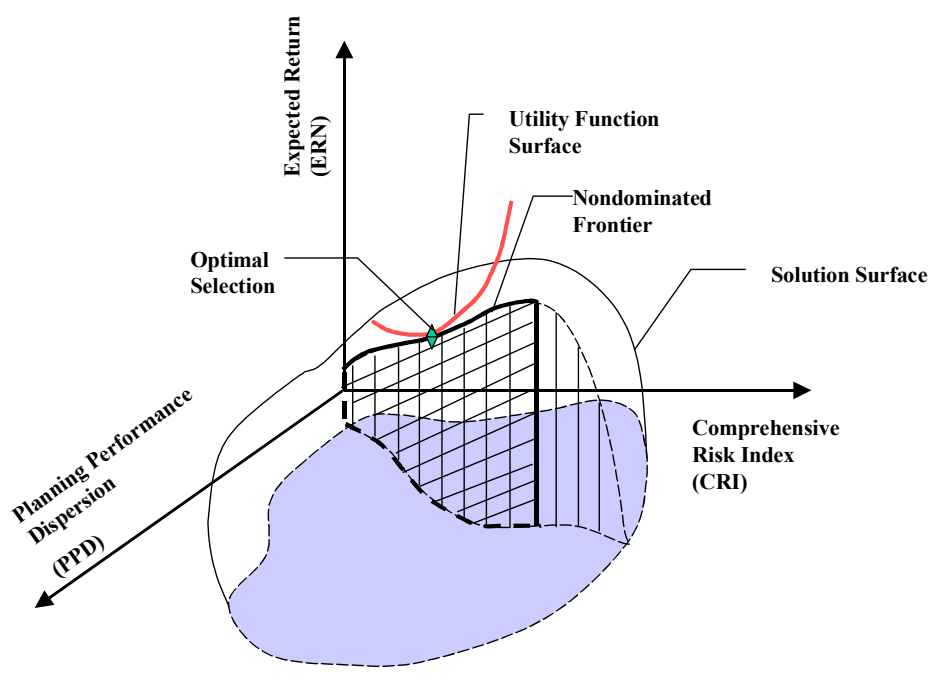


Figure 4. The Expression for Conceptual Model 